\title{
INSTITUIÇÕES INFORMAIS E PODER LOCAL: O FUNCIONAMENTO DA CÂMARA MUNICIPAL DE AMÉRICO BRASILIENSE A PARTIR DOS PROJETOS DE LEI (2010-2018)
}

\author{
INSTITUCIONES INFORMALES Y PODER LOCAL: EL FUNCIONAMIENTO \\ DEL AYUNTAMIENTO DE AMÉRICO BRASILIENSE BASADO EN LOS PROYECTOS \\ DE LEY (2010-2018)
}

\begin{abstract}
INFORMAL INSTITUTIONS AND LOCAL GOVERNMENT: THE OPERATION OF THE AMÉRICO BRASILIENSE CITY HALL BASED ON DRAFT LAWS (2010-
\end{abstract} 2018)

Renan Nakamura LOPES DA SILVA ${ }^{1}$

RESUMO: Este trabalho objetiva analisar as variáveis político-institucionais que orientam o comportamento dos vereadores na Câmara Municipal de Américo Brasiliense - SP e a relação entre Legislativo e Executivo no âmbito local. O modelo teórico utilizado enfatiza o papel das regras e instituições informais dos processos decisórios que regulam a prática política, isto é, aquelas que orientam e constrangem o comportamento dos agentes, embora não se encontrem formalmente instituídas. Os projetos considerados foram as emendas parlamentares individuais dos vereadores, que figuram como uma instituição informal a partir da qual o vereador procura atender a uma demanda específica do eleitorado e, em troca, aproxima-se da agenda proposta pelo Executivo. Os resultados apontam na direção de uma relação de complementaridade entre instituições formais e informais - isto é, relações que aumentem a eficiência das atividades legislativas -, tendo em vista o crescente protagonismo das emendas parlamentares como principais ferramentas de ação dos vereadores.

PALAVRAS-CHAVE: Instituições informais. Estudos legislativos. Américo Brasiliense. Emendas parlamentares individuais.

RESUMEN: El objetivo de este trabajo es analizar las variables político-institucionales que guían el comportamiento de los concejales en el Municipio de Américo Brasiliense - SP y la relación entre Legislativo y Ejecutivo a nivel local. El modelo teórico utilizado enfatiza el papel de las reglas e instituciones informales en los procesos de toma de decisiones que regulan la práctica política, es decir, aquellos que guían y limitan el comportamiento de los agentes, aunque no están formalmente instituidos. Los proyectos considerados fueron las enmiendas parlamentarias individuales de los concejales, que figuran como una institución informal desde la cual el concejal busca satisfacer una demanda específica del electorado y, a cambio, se acerca a la agenda propuesta por el Ejecutivo. Los resultados apuntan en la dirección de una relación complementaria entre las instituciones formales e informales, es decir, las relaciones que aumentan la eficiencia de las actividades legislativas, en vista del papel cada vez mayor de las enmiendas parlamentarias como las principales herramientas de acción de los consejeros.

1 Universidade de São Paulo (USP), São Paulo - SP - Brasil. Graduando em Letras. ORCID: https://orcid.org/0000-0002-5127-5704. E-mail: renannls96@gmail.com 
PALABRAS CLAVE: Instituciones informales. Estudios legislativos. Américo Brasiliense. Enmiendas parlamentarias individuales.

ABSTRACT: This work aims to analyze the political-institutional variables that guide the behavior of the councilors in the Municipality of Américo Brasiliense - SP and the relationship between Legislative and Executive at the local level. The theoretical model used emphasizes the role of informal rules and institutions in decision-making processes that regulate political practice, that is, those that guide and constrain the behavior of agents, although they are not formally instituted. The projects considered were the individual parliamentary amendments of the councilors, which figure as an informal institution from which the councilman seeks to meet a specific demand from the electorate and, in return, approaches the agenda proposed by the Executive. The results point in the direction of a complementary relationship between formal and informal institutions - that is, relationships that increase the efficiency of legislative activities -, in view of the increasing role of parliamentary amendments as the main action tools of councilors.

KEYWORDS: Informal institutions. Legislative studies. Américo Brasiliense. Individual parliamentary amendments.

\section{Introdução}

Esta pesquisa é uma continuação da pesquisa do ano anterior, também financiada pelo Conselho Nacional de Desenvolvimento Científico e Tecnológico (CNPq), tendo como objetivo entender as variáveis político-institucionais que orientam o funcionamento do poder Legislativo em âmbito local.

A pesquisa anterior teve como recorte temporal o período de $01 / 01 / 2013$ a 31/12/2016, referente a uma única gestão governamental de Américo Brasiliense. Nesta nova pesquisa, o recorte foi estendido de 01/01/2010 a 31/12/2018. Outra alteração foi o modelo teórico aplicado no estudo de caso, tendo em vista as dificuldades do modelo anteriormente utilizado de explicar algumas questões importantes do funcionamento da Câmara Municipal.

Primeiramente, foi selecionada a literatura especializada sobre o tema, a fim de obter maior embasamento sobre o tema, bem como compreender os métodos e instrumentos necessários para a análise do objeto de estudo. Em seguida, foram coletados os projetos de lei aprovados no período, a Lei Orgânica do Município e o Regimento Interno da Câmara, a fim de conhecer as regras institucionalizadas que permitem e limitam a atuação dos agentes no sistema político.

O modelo teórico atual, contudo, enfatiza o peso das regras informais nos trâmites decisórios, isto é, as condutas convencionadas pela prática política que também exercem 
influência na capacidade de ação das partes envolvidas. Nossa hipótese é de que as regras informais são significativas no andamento dos procedimentos da Câmara, havendo uma relação de complementaridade entre elas e as regras formalmente instituídas. Isso significa que a coexistência entre os dois tipos de regras permite uma relação eficiente do ponto de vista político, tanto dentro da Câmara quanto na relação entre os dois poderes.

Este trabalho pretende, a partir do estudo de caso, contribuir para o aprofundamento dos estudos legislativos no âmbito local, fomentando o debate do papel das instituições e regras informais do jogo político, bem como fornecendo material para novos estudos dessa área que enfatizem novas variáveis, como o perfil das elites locais, o tamanho do município, a heterogeneidade do eleitorado, entre outros.

\section{Estudos legislativos no Brasil}

Pelo menos desde o final do século XX, os estudos legislativos e institucionais têm sido o foco da Ciência Política contemporânea. Tendo em vista o processo de democratização sem precedentes que ocorreu no período 1990-2015, a demanda por conhecimento a respeito dos pilares político-institucionais que viabilizam o funcionamento da democracia representativa também cresceu intensamente (LEVITSKY; ZIBLATT, 2018).

Dentro desse contexto, o Brasil teve suas primeiras grandes contribuições no âmbito dos estudos legislativos no final da década de 90, abrindo caminho para o debate entre os modelos teóricos neo-institucionalistas que melhor explicam os trâmites decisórios no início da década seguinte, como Limongi e Figueiredo (2001) e Ames (2003). Com o tempo, as análises institucionais e legislativas foram estendidas às esferas estaduais de poder e recentemente têm se voltado para o município como objeto de estudo.

Até o regime militar, o poder local foi interpretado sob a ótica do coronelismo e do voto pessoal, na qual a figura do coronel assumia o papel de mediador de seus eleitores com o poder público estadual e federal. Nesse modelo, as grandes propriedades rurais são consideradas determinantes no processo de votação e da estrutura político-partidária da democracia brasileira, embora já demonstrasse sinais de esgotamento (LEAL, 2012).

Tais sinais estavam ligados à reformulação do território nacional. Durante esse mesmo período, o Brasil passa de uma nação majoritariamente rural para majoritariamente urbana. Essa reconfiguração acelerada teve consequências importantes do ponto de vista socioeconômico, aumentando o protagonismo das grandes cidades na economia e trazendo novos agentes sociais, que passaram a influenciar o eleitorado antes dominado pelo coronelismo. 
Segundo Kerbauy (2016), as eleições de 82 marcaram o fim do coronelismo e do mandonismo locais no seu sentido tradicional. Isso porque o governo militar apostou na capacidade de os coronéis orientarem os votos das famílias no âmbito municipal, mantendo, assim, os "velhos alinhamentos políticos"; o que se viu, contudo, foi a vitória significativa da oposição nas prefeituras do estado de São Paulo, que elegeu 310 das 572 prefeituras possíveis.

A promulgação da Carta Constitucional de 1988 trouxe novas prerrogativas e funções político-administrativas, como maior autonomia dos estados e municípios e o fortalecimento do Legislativo nacional. O processo de consolidação democrática aumentou a demanda por estudos legislativos capazes de abarcar os principais agentes e mecanismos políticoinstitucionais da democracia brasileira, incluindo as inovações do desenho institucional dos municípios.

\section{As limitações do modelo partidário}

Na pesquisa anterior, o modelo utilizado para analisar os trâmites decisórios locais foi o neo-institucionalismo de versão partidária, idealizado por Limongi (1994) ao debruçar-se sobre os estudos legislativos federais. Opondo-se à literatura que aponta para a fraqueza dos partidos em orientar os votos de seus parlamentares e ao protagonismo das comissões internas, enfatiza-se que os partidos políticos têm papel importante como mediador das votações, articulando os votos de seus deputados com as propostas do Executivo.

A versão partidária foi defendida e aplicada por Figueiredo e Limongi (2001), em que os autores buscaram entender os processos decisórios no âmbito federal brasileiro. Tendo o controle da agenda orçamentária e contando com o alto índice de disciplina partidária por parte dos parlamentares - isto é, a capacidade de o partido orientar o voto dos deputados que pertençam à legenda -, o Executivo figura no sistema político como preponderante na agenda legislativa. Essa relação foi observada a partir da interpretação das regras formalizadas do jogo, entendidas como aquelas que são levadas em consideração pelos agentes envolvidos para tomar suas decisões.

Sendo o município um ente federativo a partir da Constituição de 1988, as regras e legislações federais foram trazidas para a política local. Assim, seria possível partir da hipótese que as mesmas relações observadas na esfera federal seriam encontradas nas instituições locais:

As regras constitucionais que veiculam os princípios do processo legislativo são impositivas às três esferas de governo. Excetuado o mecanismo da medida provisória, o arcabouço legal que rege o município é basicamente o mesmo daquele identificado em nível federal. Em relação às competências privativas 
do Executivo e do Legislativo, as leis orgânicas estão sob o arcabouço da Constituição Federal. Dessa maneira, está delegado ao prefeito o mesmo arsenal de que dispõe a Presidência para ditar o processo legislativo. A hipótese aqui desenhada é que há uma forte preponderância do Executivo na formulação e aprovação da agenda dos trabalhos legislativos. Para ver sua agenda aprovada, o Executivo deve montar um governo de coalizão partidária, trazendo para a sua base de apoio uma série de partidos, os quais darão sustentação ao governo na aprovação de sua agenda legislativa. Assim, a hipótese principal do trabalho está filiada ao modelo partidário de relacionamento entre os poderes (CAETANO, 2005, p. 105).

Assim como Caetano (2005), a primeira pesquisa buscou aplicar o modelo partidário ao âmbito local. Contudo, a existência das mesmas regras formais não implica a sua efetividade na prática política. Embora os mecanismos institucionais que permitam às lideranças partidárias orientar o comportamento dos parlamentares estejam previstos na legislação, no caso de Américo Brasiliense, aquelas lideranças não figuravam como atuantes nos processos decisórios.

Outro fator que chamou a atenção foi a alta capacidade do Executivo em criar consensos na Câmara Municipal apesar da baixa atuação partidária. Na ausência dos partidos como mediadores dos interesses entre os parlamentares e o Executivo, o modelo encontra limitações em explicar a ocorrência de tais consensos.

\section{As regras e as instituições informais}

Considerando as limitações do modelo anteriormente aplicado, a presente pesquisa esteve centrada no papel das instituições informais no jogo político, isto é, aquelas que não se encontram oficializadas ou instituídas, que podem ser definidas como

expresiones acerca de la forma como se han llevado -y se siguen llevando- a cabo las relaciones al interior de una sociedad. Constituyen pues modos que recogen la historia y la cultura de comunidades enteras y están condensadas en códigos de conducta, normas sociales y convenciones que se establecen no de modo tácito sino a través del tiempo y toman forma y significado en el marco de los usos y costumbres imperantes en la sociedade (ROCHA, 2006, p. 04).

A definição de Rocha é bastante ampla, pois "códigos de conduta", "normas sociais" e “convenções" estabelecidos através de um longo período de tempo pelos costumes, podem ser identificados e analisados em diversos grupos de interação social. Deve-se enfatizar que o conceito de instituições informais não deve ser tomado como um sinônimo para cultura. Assim, é preciso estabelecer a relevância e especificidades daquelas instituições no que se refere à compreensão das instituições políticas, bem como comparar o seu impacto em relação às regras 
instituídas, há muito já consideradas como decisivas nos processos decisórios. Desse modo, as instituições informais

[...] son una fuente relevante de expresiones comportamentales y no un simple complemento -0 , de manera contraria, un residuo- de las 24 instituciones formales. Esto quiere decir que aún cuando las limitaciones formales prescriben el comportamiento individual, en el sentido de que lo reglamentan $\mathrm{y}$, con ello, se puede saber cuáles pueden ser los comportamientos esperados, en las interacciones humanas siempre existe una zona que no es abarcada por éstas. El comportamiento humano, y particularmente el comportamiento político, es tan complejo como para esperar verlo plasmado en algunas formulaciones. Si ello fuera de ese modo, en las sociedades que comparten instituciones formales similares se deberían observar los mismos resultados, pero la verdad es que los productos institucionales pueden variar y diferir considerablemente (ROCHA, 2006, p. 04).

$\mathrm{O}$ autor argumenta ainda que, comparadas às regras formalizadas, as instituições informais são de igual importância, tendo em vista a complexidade do comportamento humano e político, que dificilmente poderia ser reduzido a um conjunto de formulações previamente colocadas. Se assim fosse, seria esperado que o comportamento político fosse o mesmo em diferentes contextos contanto que as regras fossem as mesmas, mas o que se observa é a considerável variedade de comportamentos mesmo sob tais condições.

Helmke e Levitsky (2004) definem o conceito de instituição como "regras e procedimentos (formais e informais) constrangendo e permitindo a ação dos atores" envolvidos, definição considerada padrão para o termo e, em seguida, diferenciam as instituições formais das informais:

We define informal institutions as socially shared rules, usually unwritten, that are created, communicated, and enforced outside of officially sanctioned channels. By contrast, formal institutions are rules and procedures that are created, communicated, and enforced through channels widely accepted as official. This includes state institutions (courts, legislatures, bureaucracies) and state-enforced rules (constitutions, laws, regulations), but also what Robert C. Ellickson calls "organization rules," or the official rules that govern organizations such as corporations, political parties, and interest groups. Distinguishing between formal and informal institutions, however, is only half the conceptual task. "Informal institution" is often treated as a residual category, in the sense that it can be applied to virtually any behavior that departs from, or is not accounted for by, the written-down rules (HELMKE; LEVITSKY, 2004, p. 727).

No entanto, a distinção entre as instituições formais e informais não é consensual e muitas vezes acaba-se entendendo por "informal” tudo aquilo que não se encontra representado explicitamente nas regras formalmente instituídas, confundindo-o com regras fracas, corrupção 
ou simplesmente cultura. Assim, os autores propõem quatro diferenciações básicas, a fim de tornar o conceito mais preciso.

A primeira é que as instituições informais não devem ser confundidas com instituições formais fracas. Isso porque instituições ineficazes não necessariamente implicam a existência de instituições informais; as regras podem simplesmente não existir ou terem sido institucionalizadas de uma forma não eficiente, abrindo espaço para comportamentos e procedimentos não desejados, tais como o clientelismo ou o abuso de poder do Executivo (HELMKE; LEVITSKY, p. 727).

A segunda distinção é em relação a tendência de se considerar qualquer comportamento regular e informal como sendo sinais da existência de instituições informais. Tais instituições só podem ser encontradas a partir de comportamentos informais e regulares que, caso não sejam cumpridos, impliquem algum nível de "punição externa". Caso a ação informal não apresente alguma contrapartida que a constranja, não se pode tratá-la como instituição informal. A terceira distinção proposta é entre instituições informais e organizações informais. Na visão dos autores, é útil diferenciar as regras dos atores envolvidos.

A quarta e última distinção é em relação ao conceito de cultura. Embora os autores reconheçam que instituições informais podem ser criadas e transmitidas por meio da cultura, esta última é sempre tratada como uma rede compartilhada de valores societários. Já as instituições informais, do ponto de vista dos autores, devem ser compreendidas mais através do compartilhamento de expectativas, expectativas essas que podem ou não estar enraizadas na cultura (HELMKE; LEVITSKY, 2004, p. 728).

Ao precisar o conceito de instituições informais, os autores contribuem para a dissociação entre aquele conceito e ineficiência política ou institucional. A implicação direta dessa contribuição é que a articulação entre o formal e o informal define o tipo de comportamento esperado nas instituições a que se pretende analisar. Em outras palavras, instituições informais e formais podem convergir tanto para o bom quanto ao mau andamento dos processos decisórios.

Quadro 1 - Tipologia das instituições informais 


\begin{tabular}{|c|c|c|}
\hline Resultados & Instituições informais eficazes & Instituições informais ineficazes \\
\hline Convergente & Complementares & Substitutivas \\
\hline Divergente & Acomodativas & Competitivas \\
\hline
\end{tabular}

Fonte: Helmke e Levitsky (2004, p. 728)

A fim de classificar as diferentes combinações entre instituições informais e formais, é preciso compará-las com o grau de convergência ou divergência entre elas. Compreendem-se instituições informais como complementares aquelas que, ao serem colocadas em prática, facilitam os trâmites políticos, de modo a garantir a realização dos resultados esperados pelas regras escritas. A convergência complementar tende a ser positiva na fundação de novas instituições, criando ou aumentando os incentivos para que sejam praticadas regras que apenas existem no papel (HELMKE; LEVITSKY, 2004, p. 728).

Instituições informais acomodativas são esperadas quando as instituições informais incentivam resultados que alteram substantivamente o efeito das regras formalizadas, mas sem violá-las; as regras formais são contraditas em espírito, mas não no seu conteúdo (HELMKE; LEVITSKY, p. 729). Nesses dois casos, as instituições formais funcionam de forma efetiva.

Quando os resultados esperados são divergentes e as instituições formais, ineficazes, têm-se instituições informais competitivas. Isto é, são instituições incompatíveis com as regras formalizadas, fazendo com que, para que se siga uma das regras, seja necessário violar a outra (HELMKE; LEVITSKY, p. 729). Os exemplos mais trabalhados pela Ciência Política contemporânea são clientelismo, patrimonialismo e corrupção, sendo mais encontrados em países que passaram por um processo de descolonização.

Por fim, as instituições informais substitutivas são aquelas em que as instituições formais são ineficazes, porém compartilham os mesmos resultados. Assim como as instituições informais complementares, as substitutivas buscam uma convergência de resultados com as instituições formais, mas elas ganham espaço onde as regras formais não são reforçadas e divulgadas, como as instituições competitivas (HELMKE; LEVITSKY p. 729). Tais instituições tendem a aparecer onde a estrutura estatal é fraca, no sentido de não possuir a devida autoridade.

Martins e Kerbauy (2018), ao analisarem o comportamento do Executivo e do Legislativo, no município de São Carlos - SP, valem-se das instituições informais para compreendê-lo. Para isso, as autoras analisam as emendas parlamentares, entendidas "enquanto uma regra informal que incide sobre as trocas políticas, o comportamento dos vereadores e o processo legislativo no município de São Carlos - SP (MARTINS; KERBAUY, 2018). Tendo 
em vista a baixa quantidade de estudos referentes à esfera local, nesta perspectiva, optaram pelo estudo de caso.

Geralmente os estudos que focam na relação entre os poderes abordam a "distribuição de pastas e as nomeações políticas como um recurso para a gestão da coalizão" (MARTINS; KERBAUY, 2018). Por outro lado, no caso do município,

[...] a depender de seu porte e da magnitude eleitoral, por vezes, o vereador é o único representante de seu partido, de modo que a sigla pode não exercer efetiva coordenação legislativa. Assim, as emendas parlamentares que são dispositivos individuais podem condicionar comportamentos, atendendo aos interesses específicos dos vereadores. Isso não significa que a distribuição de cargos - reconhecidas como regras formais - não tenha peso significativo em âmbito local; mas é importante atentar para outros dispositivos (MARTINS; KERBAUY, 2018, p. 14).

O estudo de Martins e Kerbauy, ao voltar-se para a esfera local, analisa o papel da instituição informal com incidência sobre o comportamento político tão importante quanto as regras propriamente formalizadas. O presente trabalho espera contribuir para a criação de mais material a respeito dessa temática, para que, futuramente, os estudos possam analisar o impacto das instituições informais no poder local de um ponto de vista comparativo.

\section{Regras informais e emendas parlamentares}

Como colocado anteriormente, os dados referentes aos projetos aprovados entre 01/01/2010 a 31/12/2018 permitem uma análise mais abrangente dos procedimentos das atividades legislativas. No quadro 2, os projetos aprovados foram classificados de acordo com a autoria e tipo de lei. Foram contabilizadas 243 matérias legislativas, sendo 193 Leis Ordinárias, 36 Leis Complementares, 2 Leis Orgânicas e 14 Resoluções. Os dados oficiais da Câmara Municipal de Américo Brasiliense não são divulgados de forma padronizada, o que impossibilitou o reconhecimento dos autores e a votação dos vereadores dos projetos aprovados entre 2010 e 2012:

Quadro 2 - Projetos de lei aprovados por autoria e tipo (2013-2018) 


\begin{tabular}{|l|r|r|r|r|}
\cline { 2 - 5 } \multicolumn{1}{c|}{} & Ordinária & Complementar & Orgânica & Resolução \\
\hline Executivo Municipal & 143 & 28 & 2 & - \\
\hline Vereadores & 48 & 1 & - & - \\
\hline Mesa Diretora & 2 & 7 & - & 14 \\
\hline
\end{tabular}

Fonte: Site da Câmara Municipal²

A partir dessa primeira relação dos dados, pode-se notar a preponderância do Executivo frente à atividade legislativa, tanto nas Leis Ordinárias $(74,8 \%)$ quanto nas Leis Complementares $(77,7 \%)$. No entanto, tais números não são suficientes para sugerir uma relação conflituosa entre o Executivo e o Legislativo, no sentido de que a ação parlamentar esteja sendo orientada por ameaças ou possíveis sanções vindas do Executivo. É importante ressaltar que os dados sugerem que a atividade dos parlamentares é centrada quase que integralmente nos projetos de Lei Ordinária, representando 24,08\% do total de Leis Ordinárias aprovadas.

As emendas parlamentares individuais consistem no "repasse de recursos a entidades municipais", que podem ter diferentes fins, tendo como objetivo atender às múltiplas demandas das bases eleitorais dos vereadores (KERBAUY; MARTINS, 2018, p. 15). Assim, as matérias legislativas vindas dos vereadores foram classificadas de acordo com o seu propósito, tendo em vista identificar as emendas dentre tais projetos.

$\mathrm{Na}$ tabela a seguir, as emendas parlamentares foram classificadas de acordo com o conteúdo enunciado. A categoria "Outros" engloba os projetos cujos conteúdos eram particulares, isto é, não apresentavam semelhança temática com nenhum outro projeto $(18,7 \%)$. Os projetos foram divididos em dois períodos diferentes, 2013-2016 e 2017-2018, pois foram encontradas mudanças significativas nos conteúdos predominantes das matérias legislativas aprovadas:

Quadro 3 - Emendas classificadas por conteúdo (2013-2018)

${ }^{2}$ Disponível em: http://www.camaraamericobrasiliense.sp.gov.br/. Acesso em: 29 jun. 2020. 


\begin{tabular}{|c|r|r|}
\hline Conteúdo/Temática & 2013-2016 & $\mathbf{2 0 1 7 - 2 0 1 8}$ \\
\hline Denominação de via pública & 17 & 1 \\
\hline Denominação de Próprio Público Municipal & 6 & 3 \\
\hline Alteração/revogação de textos de lei & 1 & 4 \\
\hline Instituição de eventos/programas & 1 & 3 \\
\hline Outros & 6 & 17 \\
\hline Total & 31 & \\
\hline
\end{tabular}

Fonte: Site da Câmara Municipal ${ }^{3}$

\section{As emendas como regras informais}

Observando o Quadro 3, nota-se que, no período 2013-2016, a atividade legislativa em Américo Brasiliense era predominantemente marcada por projetos que tratavam de denominação de via pública ou de Próprio Público Municipal, e mais um - que está representado em "Outros" -, referente à denominação de uma praça local. Ao todo, tais atividades representam $77,4 \%$ dos projetos do período, constatação que parece confirmar o "senso comum" da literatura especializada, que tratava o município como um ambiente de decisões "paroquiais" (CAETANO, 2005, p. 102).

O período de 2017-2018, em relação aos anos anteriores considerados para esta pesquisa, apresenta uma precisão maior no que se refere à sistematização dos dados oficiais da Câmara. É importante destacar que, nesse mesmo período, há um aumento expressivo na quantidade de matérias legislativas aprovadas, quando comparada aos anos anteriores. Em 2013-2016, o total foi de 119 projetos, ao passo que, em 2017-2018 - portanto, metade da duração do período anterior -, foram contabilizados 126 projetos.

No entanto, no período 2017-2018, os projetos sobre denominação de vias públicas diminuem drasticamente, aparecendo apenas uma vez. Em contrapartida, houve aumento significativo no número de projetos que envolvam alteração ou revogação de textos de lei e principalmente de instituição de eventos/programas de diversas categorias, como cultural, assistencial, esportivo, eventos de conscientização e entretenimento.

Essas últimas (emendas referentes à instituição de eventos/programas) tendem a estar de acordo com as demandas de grupos específicos do município, todos enviados por vereadores

${ }^{3}$ Disponível em: http://www.camaraamericobrasiliense.sp.gov.br/. Acesso em: 29 jun. 2020. 
e aprovados como Leis Ordinárias. Pode-se notar, dessa forma, que, no período analisado, as emendas parlamentares começam a ganhar espaço nas matérias legislativas. Assim, as emendas individuais, ao lado das alterações e revogações de lei, têm se mostrado como atividade principal dos vereadores em termos de aprovação de projetos.

Dos projetos enviados pelos vereadores que tiveram disponíveis suas respectivas votações, a grande maioria foi aprovada de forma unânime na Câmara, 97,5\%. Embora esteja instituído a possibilidade de as bancadas partidárias intervirem no processo político, as decisões parecem ter seguido caminhos acordados pelos próprios vereadores e prefeitos, não havendo evidências de uma intervenção significativa das legendas partidárias.

\section{Instituições informais complementares}

Como apontam Kerbauy e Martins (2018), municípios de pequena magnitude eleitoral geralmente apresentam baixa participação das legendas - como é o caso de Américo Brasiliense -, uma vez que os vereadores podem ser os únicos representantes dos seus partidos (KERBAUY; MARTINS, 2018, p. 14). Nesse contexto, as emendas parlamentares podem aparecer como importantes ferramentas por meio das quais os vereadores orientam seus comportamentos, aproximando-se do Executivo municipal e buscando atender às demandas de grupos específicos que compõem o eleitorado.

Seguindo a tipologia proposta por Helmke e Levitsky (2004), a pesquisa aponta para uma possível relação de complementaridade entre as regras formais e informais dos processos decisórios, uma vez que as emendas parlamentares não infringem nenhuma regra instituída e parecem convergir para os resultados esperados pelas instituições formais, favorecendo a eficiência dos processos decisórios.

Embora não escritas, as emendas surgem como uma regra informal que permite a aproximação com as propostas do Executivo, num contexto de aumento do número de matérias legislativas - principalmente no período 2017-2018 - e de mudança dos conteúdos dos projetos. Tais conteúdos têm passado de matérias predominantemente referentes a denominações oficiais para matérias que dispõem sobre alteração ou revogação de leis e principalmente sobre a criação ou oficialização de eventos e programas para grupos e fins específicos.

Em se tratando de uma mudança que parece ter ganhado força nos dois últimos anos, é difícil afirmar que as emendas parlamentares já tenham se consolidado como um mecanismo indispensável para o andamento dos processos decisórios, como é no caso de São Carlos analisado por Kerbauy e Martins (2018). De qualquer forma, levá-las em consideração, bem 
como quaisquer outras instituições informais que venham a ser identificadas, é necessário, para que seja possível compreender de maneira mais precisa os comportamentos dos atores e regras que efetivamente os constrangem e orientam.

\section{Considerações finais}

Partindo dos projetos de lei aprovados no período 2013-2016, a pesquisa anterior buscou analisar as variáveis que orientam o comportamento dos atores envolvidos nas atividades legislativas de Américo Brasiliense. Nessa primeira coleta de dados, o modelo teórico utilizado foi o proposto por Limongi e Figueiredo (2001), que defendia a preponderância do Executivo nas matérias legislativas ao considerar os mecanismos político-institucionais formalizados no Regimento Interno e na Lei Orgânica do Município como formas de constranger o comportamento dos parlamentares, como a possibilidade de pedir o Requerimento de Urgência e o controle sobre a agenda orçamentária.

Com essas regras postas, as lideranças partidárias apareceriam como figuras importantes para orientar o comportamento de seus parlamentares e na negociação com o poder Executivo. No entanto, dois apontamentos são necessários: 1) O modelo foi originalmente criado para a análise da esfera federal; simplesmente aplicá-lo ao município sem atentar às especificidades desse último poderia enfraquecer a análise, pois, como apontam Martins (2015) e Kerbauy (2014). O perfil das elites locais, variações regionais e a magnitude do eleitorado influenciam o andamento do sistema político. Embora as regras instituídas no município fossem semelhantes às regras no âmbito federal, a sua aplicação não ocorreu da mesma forma. Como coloca Rocha (2006), a simples existência de regras iguais em contextos diferentes não implica resultados e comportamentos iguais.

No caso de Américo Brasiliense, as lideranças partidárias exerceram pouca influência sobre seus vereadores; as decisões foram tomadas numa relação direta dos parlamentares com a Prefeitura do município. Durante esse processo, a votação das matérias legislativas foi unânime na grande maioria das vezes, sugerindo uma aproximação entre os atores envolvidos. Trazer as regras informais como variáveis a serem observadas abriu novas possibilidades de explicação dos processos decisórios nesse contexto, uma vez que os mecanismos políticoinstitucionais que beneficiam o Executivo e as legendas não eram colocados em prática.

O período entre 2016 e 2018 sugere uma mudança nos tipos de propostas que passaram pela Câmara. Conforme analisado na seção 4, houve um aumento na quantidade de matérias legislativas a serem votadas e uma mudança significativa nos conteúdos sobre os quais as 
matérias tratavam. Os trabalhos legislativos eram notadamente marcados pela denominação de vias públicas e Próprios Públicos até 2016, mas, a partir deste período, estas denominações caíram drasticamente.

Os vereadores começaram a enviar emendas de conteúdos programáticos, como alteração ou revogação de textos de lei e oficialização de eventos culturais, eventos esses que tendem a ser de interesse de grupos específicos dentro do eleitorado. Assim, a análise sugere que as emendas parlamentares começam a ganhar espaço na atividade legislativa do município como uma forma de aproximar os poderes.

Esta pesquisa por se tratar de um estudo de caso, não pretende abranger todas as variáveis relevantes para a análise do comportamento dos políticos local. Ainda que os dados deste estudo de caso apontem na direção de complementariedade entre regras formais e informais, são necessários mais estudos comparativos que busquem qualificar o impacto das regras informais no jogo político.

Há outras variáveis importantes que orientem a atuação daquelas regras, como as características socioeconômicas de cada município (KERBAUY, 2014), o perfil das elites políticas locais (MARTINS, 2015), a magnitude do eleitorado (KERBAUY; MARTINS 2018) e a composição da Câmara, que varia a cada período eleitoral. Esperamos contribuir para essa discussão, fornecendo dados para pesquisas futuras que consigam abranger tais variáveis e aprofundem o conhecimento sobre o funcionamento da política municipal.

\section{REFERÊNCIAS}

\section{AMÉRICO BRASILIENSE. Câmara Municipal. Lei Orgânica Municipal de Américo}

Brasiliense. 2017. Disponível em: http://www.camaraamericobrasiliense.sp.gov.br/leis/leiorganica-municipal. Acesso em: 19 fev. 2018.

AMÉRICO BRASILIENSE. Câmara Municipal. Regimento Interno. 2015. Disponível em: http://www.camaraamericobrasiliense.sp.gov.br/leis/regimento-interno/formato-pdf/view. Acesso em: 19 fev. 2018.

CAETANO, B. Executivo e Legislativo na esfera local. Agendas e construção de maiorias na Câmara Municipal de São Paulo. Revista Novos Estudos, v. 1, n. 71, p. 100-125, mar. 2005. Disponível em: http://novosestudos.uol.com.br/produto/edicao-71/. Acesso em: 19 maio 2019.

FIGUEIREDO, A. LIMONGI, F. Executivo e Legislativo na nova ordem constitucional. Rio de Janeiro: Editora FGV, 2001.

HELMKE, G.; LEVITSKY, S. Informal Institutions and Comparatives Politics: a Research Agenda. Perspectives on Politics, Nova York, v. 2, n. 4, pp.725-740, 2004. Disponível em: 
https://pdfs.semanticscholar.org/bbc2/7446e63d48bf7ac1bd4713562cd82414c42b.pdf. Acesso em: 17 maio 2019.

HELMKE, G.; LEVITSKY, S. Informal institutions and democracy: lessons from latin america. Baltimore: The Johns Hopkins University Press, 2006. Disponível em: https://books.google.com.br/books?hl=pt-

BR\&1r=\&id=WT2OiQQg508C\&oi $=$ fnd $\& p g=$ PR7\&dq=Informal + Institutions + and + Democrac $\mathrm{y}:+$ Lessons + from+Latin+America. + Baltimore:+The+Johns + Hopkins + University + Press,+200 6.\&ots=qm7_DvBfnP\&sig $=$ Yt3Hk0wwdafIkJbTZLyV2Mmgg70\#v=onepage \&q\&f=false. Acesso em: 17 maio 2019.

KERBAUY, M. T. M. "Padrões regionais de votação nas eleições municipais brasileiras". In: KERBAUY, M. T. M. ROCHA, M. M. (org.). Eleições, partidos e representação política nos municípios brasileiros. Juiz de Fora: Editora UFJF, 2014. p. 79-107.

KERBAUY, M. T. M. A morte dos coronéis. Curitiba: Appris Editora, 2016.

KERBAUY, M. T. M. Câmaras Municipais, Partidos e Negociações Políticas. In:

CONGRESSO INTERNACIONAL DA BRAZILIAN STUDIES ASSOCIATION - BRASA, 9., 2008, Nova Orleans. Proceedings [...]. Nova Orleans, Louisiana: Tulane University em Nova Orleans, mar. 2008. Disponível em:

http://www.brasa.org/wordpress/Documents/BRASA_IX/Maria-Kerbauy.pdf. Acesso em: 17 maio 2019.

KERBAUY, M. T. M. MARTINS, T. C. Instituições Informais, Trocas Políticas e Emendas Parlamentares no Contexto Municipal. In: ENCONTRO DA ASSOCIAÇÃO BRASILEIRA DE CIÊNCIA POLÍTICA - ABCP, 11., 2018, Curitiba. Anais [...] Curitiba, 2018. Disponível em - https://cienciapolitica.org.br/_arquivos/encontro-abcp-2018/arquivos/BYGN.pdf. Acesso em: 25 abr. 2019

LEVITSKY, S. ZIBLATT, D. Como as democracias morrem. São Paulo: Editora Zahar SP, 2018.

LIMONGI, F. O novo institucionalismo e os estudos legislativos: a literatura norte-americana recente. Revista Brasileira de Informação Bibliográfica em Ciências, Rio de Janeiro, n. 37 , p. 3-38, 1994.

MARTINS, T. C. Organização e funcionamento da política representativa local: o caso do município de São Carlos. Agenda Política, São Carlos, v. 3, n. 2, p. 184-209, jul./dez. 2015.

ROCHA, R. Instituciones Informales y Calidad de la Política: Entre la Cultura y la Subjetividad Política. In: SÁNCHEZ, C. (coord.). Psicología Alternativa en América Latina. AMAPS, 2006. 


\section{Como referenciar este artigo}

SILVA, R. N. L. Instituições informais e poder local: o funcionamento da câmara municipal de Américo Brasiliense a partir dos projetos de lei (2010-2018). Rev. Sem Aspas, Araraquara, v. 9, n. 1, p. 104-119, jan./jun., 2020. e-ISSN: 2358-4238. DOI: https://doi.org/10.29373/sas.v9i1.13923

Submetido em: $15 / 06 / 2020$

Revisões requeridas: $20 / 08 / 2020$

Aprovado em: 28/08/2020

Publicado em: 30/09/2020 